\title{
STRATEGI PEMASARAN UPT MUSEUM BALANGA SEBAGAI WISATA EDUKASI DI KOTA PALANGKARAYA
}

\author{
Inten Larasaty \\ Program Magister Tata Kelola Seni \\ Institute Seni Indonesia Yogyakarta, Yogyakarta, Indonesia \\ e-mail : intanlarasaty051@gmail.com
}

Diterima : 30 Juli 2020. Disetujui : $2 \underline{5}$ November 2020. Dipublikasikan : 1 Desember 2020 (c) () $\begin{aligned} & \text { C2020- DESKOVI Universitas Maarif Hasyim Latif. Ini adalah artikel dengan akses } \\ & \text { terbuka di bawah lisensi CC BY } 4.0 \text { (https://creativecommons.org/licenses/by/4.0/) }\end{aligned}$

\begin{abstract}
ABSTRAK
Keberadaan museum selama ini sering dianggap hanya sebagai tempat memamerkan koleksi budaya maupun sejarah saja, padahal sebenarnya dapat menjadi alternatif yang menarik untuk dikunjungi wisatawan. Kesan membosankan yang menjadi polemik di berbagai museum di Indonesia harus ditepis dengan melakukan strategi pemasaran yang tepat. Salah satunya yaitu UPT Museum Balanga yang merupakan museum budaya di Kota Palangkaraya. Museum Balanga selain memiliki tempat yang strategis juga memiliki keunikan dari berbagai koleksi yang menunjukkan siklus hidup suku Dayak. Kenyataannya dari data pengunjung yang dihasilkan pada setiap tahun ternyata masih belum mencapai peningkatan yang maksimal. Penelitian ini dilakukan dengan pendekatan kualitatif bersifat deskriptif dengan menggunakan analisis SWOT. Tahap penelitian dilakukan dengan mengumpulkan data, kemudian tahap analisis dengan membandingkan antara faktor eksternal peluang dan ancaman dengan faktor internal kekuatan dan kelemahan, dan yang terakhir yaitu tahap penetapan strategi berdasarkan marketing mix $7 \mathrm{p}$ yaitu product, price, place, promotion, process, people, dan physical evidence. Tujuan penelitian ini yaitu menganalisis kelebihan dan kekurangan pada UPT Museum Balanga serta memformulasikan strategi pemasaran yang tepat untuk meningkatkan daya tarik dan jumlah pengunjung lokal maupun mancanegara. Pada hasil penelitian ini menunjukkan bahwa UPT museum balanga perlu meningkatkan servis excellence dengan melakukan training dan menetapkan standar operasional pegawai, pembenahan terhadap interior dan eksterior desaign, melengkapi berbagai fasilitas penunjang seperti ruang multimedia, cafe dan lainnya, serta meningkatkan promosi dengan memanfaatkan berbagai media sosial dan bekerjasama dengan pihak-pihak terkait.
\end{abstract}

Kata kunci: analisis swot, marketing mix 7p, museum, museum balanga, strategi, wisata

\begin{abstract}
The existence of museums has often been considered only as a place to display cultural and historical collections, when in fact it can be an interesting alternative place for tourists to visit. The boring impression that became polemic in various museums in Indonesia must be erased by carrying out the right marketing strategy. One of them is UPT Museum Balanga which is a cultural museum in Palangkaraya City. Besides having a strategic place, Balanga Museum also has uniqueness on various collections that shows the life cycle of Dayak tribe. But the fact is that the visitor data generated each year has not yet reached the maximum increase. This research was conducted with a descriptive qualitative approach using SWOT analysis. The research stage is carried out by collecting data, then the analysis phase by comparing the external factors of opportunity and threat with the internal factors of strengths and weaknesses. In the last step to support the SWOT analysis, the writer uses marketing mix 7p, which are product, price, place, promotion, process, people, and physical evidence. The purpose of this study is to analyze the strengths and weaknesses of the UPT Museum Balanga and formulate an appropriate marketing strategy to increase the attractiveness and the amount of local and foreign visitors. The results of this study indicate that the UPT Museum Balanga needs to improve service excellence by conducting training and establishing operational standards for employees, improving the interior and eksterior design, equipping various supporting facilities such as multimedia rooms, cafes and others, and increasing promotion by utilizing various social media and collaborating with related parties.
\end{abstract}

Keywords: marketing mix 7p, museum, balanga museum, strategy, swot analysis, tourism 


\section{PENDAHULUAN}

Kepariwisataan memiliki peran yang cukup signifikan di suatu negara melalui kontribusinya dalam mempromosikan ekonomi dan pembangunan, memberi kesempatan kerja bagi masyarakat, serta turut andil dalam pelestarian kebudayaan. Sustainable Development Goals (SDGs) yang ditetapkan PBB menjadikan peran kepariwisataan berkelanjutan dalam target pencapaiannya hingga 2030. UNWTO (Ardika, 2018) menggarisbawahi ada tiga tujuan penting dalam SDGs yaitu tujuan ke-8 dengan fokus terhadap ekonomi dan membuka akses kerja untuk semua orang (decent work and economi), tujuan ke-12 dengan fokus pengembangan dan memastikan produksi yang bertanggungjawab (responsible consumption and production) dan tujuan ke-14 yaitu upaya dalam konservasi dan pelestarian (life below water).

Peran museum sebagai daya tarik wisata memiliki banyak dampak positif terutama dalam pendidikan untuk mengenalkan sisi sejarah dan budaya dari suatu daerah, hanya saja sampai sekarang belum menjadi alternatif tujuan wisata yang diminati oleh banyak masyarakat. Keadaan ini rata-rata menjadi polemik di berbagai museum di Indonesia. Daranca (2015) dalam jurnalnya menggarisbawahi pengembangan yang tepat terhadap suatu museum yaitu salah satunya melalui program-program secara berkala agar menempis kesan membosankan dan menarik minat wisatawan ketika berkunjung.

Museum Balanga merupakan museum yang terdapat di Kota Palangkaraya yang mulai digunakan dari 6 April 1973, disahkan menjadi Museum Negeri Provinsi Kalimantan Tengah pada tahun 1990. Kemudian berdasarkan peraturan Gubernur N0. 64 Tahun 2008 menjadi UPT Museum Kalimantan Tengah. Berdasarkan program pengembangannya kini berorientasi sebagai pendidikan yang bersifat budaya dengan mengenalkan dan melakukan konservasi terhadap benda-benda budaya Suku Dayak. Internal Council of Museum (ICOM, 2019) menjelaskan definisi museum sebagai "museums are democratising, inclusive, and polyphonic spaces for critical dialogue about the pasts and the futures. Acknowledging and addressing the conflicts and challenges of the present, they hold artefacts and specimens in trust for society, safeguard diverse memories for future generations and guarantee equal right and equal access to heritage for all people. Museums are not for profit. They are participatory and transparent, and work in active partnership with and for diverse communities to collect, preserve, research, interpret, exhibit, and enhance understandings of the world, aiming to contribute to human dignity and social justice, global equality and planetary wellbeing". Kehadiran museum dalam hal ini secara jelas tidak hanya sebatas ajang memamerkan, dengan demikian fungsi lainnya dari museum adalah untuk (1) mengumpulkan berbagai koleksi yang meliputi cagar budaya, bangunan cagar budaya dan/atau struktur cagar budaya seperti dari alam dan lingkungan; (2) melakukan pelestarian koleksi; (3) mendokumentasikan koleksi untuk tujuan ilmu pengetahuan maupun penelitian; (4) melakukan riset dan pengembangan koleksi.

Konsep pemasaran menjadi aspek yang penting dalam pengembangan sebuah museum terutama dalam upaya meningkatkan jumlah pengunjung dengan menentukan alternatif strategi untuk mengatasi berbagai permasalahan internal maupun eksternal. Dalam Journal of Sustainable Tourism (Vol 25, 2017-Issue 7) juga menegaskan konsep sustainability marketing dalam memanfaatkan ilmu pemasaran untuk tujuan yang baik, menghindari perilaku yang terlalu eksploitatif terutama terhadap lingkungan dan budaya dengan melihat kebutuhan pasar secara efektif serta melakukan pengembangan produk berkelanjutan. Selain itu dalam Peraturan Pemerintah No. 50 Tahun 2011 tentang RIPPARNAS 2010-2025 (Ardika, 2018) juga menegaskan salah satu diantaranya fokus penting dalam pembangunan kepariwisataan nasional yaitu meningkatkan pemasaran pariwisata yang mengacu pada empat hal yaitu pengembangan pasar wisatawan, pengembangan citra pariwisata, pengembangan kemitraan pemasaran pariwisata dan pengembangan promosi pariwisata.

Mengulik dari segi pemasaran yang terjadi pada saat ini, UPT Museum Balanga masih dalam tahap perkembangan yang dapat diamati dari hasil rekapitulasi pengunjung dibeberapa tahun terakhir justru mengalami penurunan. Keadaan ini tentu tidak diharapkan oleh pemerintah daerah dan juga pengelola. Strategi pemasaran dalam hal ini bertujuan untuk mengatur kebijakan dalam pengelolaan museum yang mengacu pada prinsip pelaksanaan sustainability marketing dengan melihat $7 \mathrm{P}$ yaitu product, promotions, price, place, people, physical evidence, dan process (Utama, 2016: 16). Dampak yang diharapkan yaitu dengan bertambahnya kunjungan wisatawan lokal maupun mancanegara untuk berkunjung ke UPT Museum Balanga di Kota Palangkaraya.

Tabel 1. Rekapitulasi Pengunjung Museum Balanga

(Sumber: Dokumen UPT Museum Balanga 2019)

\begin{tabular}{|c|c|c|}
\hline No. & Tahun & Jumlah Pengunjung \\
\hline 1 & 2010 & 7.456 \\
\hline 2 & 2011 & 6.350 \\
\hline 3 & 2012 & 11.335 \\
\hline 4 & 2013 & 16.591 \\
\hline 5 & 2014 & 2.858 \\
\hline 6 & 2015 & 2.619 \\
\hline 7 & 2016 & 5.000 \\
\hline 8 & 2017 & 10.097 \\
\hline 9 & 2018 & 6.755 \\
\hline 10 & 2019 & 3.731 \\
\hline
\end{tabular}

Berdasarkan latar belakang yang telah diuraikan maka dapat dirumuskan pertanyaan penelitian sebagai berikut : (1) apa aja faktor kelebihan dan kekurangan pada Museum Balanga di Kota 
Palangkaraya dan (2) bagaimana formulasi strategi pemasaran di Museum Balanga. Sedangkan tujuan yang ingin dicapai dalam penelitian ini adalah: (1) menganalisis faktor kelebihan dan kekurangan dalam upaya pengembangan daya tarik di Museum Balanga dan (2) merumuskan formulasi strategi pemasaran di Museum Balanga dalam meningkatkan jumlah kunjungan para wisatawan.

Manfaat dari penelitian diharapkan dapat memberi konstribusi sebagai berikut : (1) secara praktis diharapkan dapat memberikan suatu alternatif dalam pengambilan kebijakan terutama kepada pihak-pihak pengelola terkait dalam menentukan strategi pemasaran yang tepat di UPT Museum Balanga; (2) secara teoritis diharapkan dapat memberikan kontribusi yang bersifat akademis dalam melengkapi kajian terhadap aspek kepariwisataan dan museum yang berkenaan dengan strategi pemasaran.

\section{METODE PENELITIAN}

Penelitian ini dilakukan di UPT Museum Balanga Kota Palangkaraya dengan menggunakan penelitian kualitatif melalui pengumpulan data primer dan data sekunder. Data primer diperoleh dari lokasi penelitian melalui observasi, wawancara dan dokumentasi. Wawancara mendalam dilakukan terhadap tenaga kerja yang terlibat seperti Kepala UPT, dan para pegawai sekaligus pemandu Museum Balanga. Sedangkan data sekunder diperoleh dari dukungan jurnal, surat kabar, dan lainnya. Penelitian ini menggunakan analisis SWOT dengan tahap analisis yaitu (1) tahap pengumpulan data, (2) tahap analisis dengan membandingkan antara faktor eksternal peluang (opportunities) dan ancaman (threats) dengan faktor internal kekuatan (strengths), dan (weaknesses) (3) Pada tahap akhir peneliti menggunakan marketing mix 7p untuk menetapkan strategi pemasaran di UPT Museum Balanga Kalimantan Tengah. Rangkuti (2016) menjelaskan bahwa SWOT merupakan singkatan dari lingkungan internal Strengths dan Weaknesses serta lingkungan eksternal Opportunities dan Threats. Analisis SWOT membandingkan antara faktor eksternal peluang (opportunities) dan ancaman (threats) dengan faktor internal kekuatan (strengths), dan (weaknesses).

Tabel 2. Analisis SWOT

(Sumber: Rangkuti, 2016)

\begin{tabular}{|c|c|c|}
\hline & $\begin{array}{l}\text { Strengths }(\mathrm{S}) \\
\text { Faktor Kekuatan }\end{array}$ & $\begin{array}{l}\text { Weakness (W) } \\
\text { Faktor } \\
\text { Kelemahan }\end{array}$ \\
\hline $\begin{array}{l}\text { Opportunities } \\
\text { (O) } \\
\text { Faktor Peluang }\end{array}$ & $\begin{array}{l}\text { Strategi SO } \\
\text { Ciptakan strategi } \\
\text { yang } \\
\text { menggunakan } \\
\text { kekuatan untuk } \\
\text { memanfaatkan } \\
\text { peluang }\end{array}$ & $\begin{array}{l}\text { Strategi WO } \\
\text { Ciptakan strategi } \\
\text { yang } \\
\text { meminimkan } \\
\text { kelemahan untuk } \\
\text { memanfaatkan } \\
\text { peluang }\end{array}$ \\
\hline
\end{tabular}

\begin{tabular}{|l|l|l|}
\hline Threaths (T) & Strategi ST & Strategi WT \\
Faktor & Ciptakan strategi & Ciptakan strategi \\
Ancaman & yang & yang \\
& menggunakan & meminimkan \\
& kekuatan untuk & kelemahan dan \\
& mengatasi & menghindari \\
& ancaman & ancaman \\
\hline
\end{tabular}

\section{HASIL DAN PEMBAHASAN}

UPT Museum Balanga dibangun oleh Pemerintah Daerah (Pemda) dibawah Pembinaan Dinas Kebudayaan dan Pariwisata Kalimantan Tengah. Berbagai program pengembangan wajib museum yang dijalankan selama ini yaitu:

a. Mengumpulkan dan mendokumentasi bendabenda budaya (artefaks) dan sumber daya alam dari Kalimantan Tengah

b. Pengadaan benda-benda budaya untuk dipamerkan kepada masyarakat

c. Mengkonservasikan benda-benda budaya untuk dipamerkan kepada masyarakat

d. Menyajikan benda-benda budaya yang dapat menarik minat publik datang ke museum, sehingga berfungsi sebagai tempat pendidikan, penelitian, dan rekreasi.

Selain melakukan pengembangan diatas, UPT museum balanga juga melakukan serangkaian beberapa kegiatan diantara adalah (1) Ritual Mamparasih Ramu yang bertujuan untuk menghilangkan pengaruh-pengaruh yang tidak baik di museum (dilaksanakan setiap tahun), (2) kegiatan mengenalkan cara merawat benda pusaka kepada pelajar (dilaksanakan oktober 2019), (3) perayaan hari jadi Museum, (4) kegiatan cerdas cermat, (5) lomba melukis.

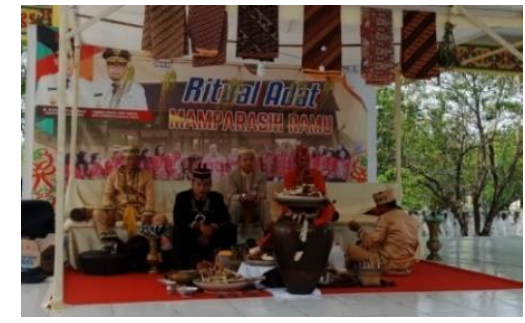

Gambar 1. Ritual mamparasih ramu (sumber;kalteng.pos.co

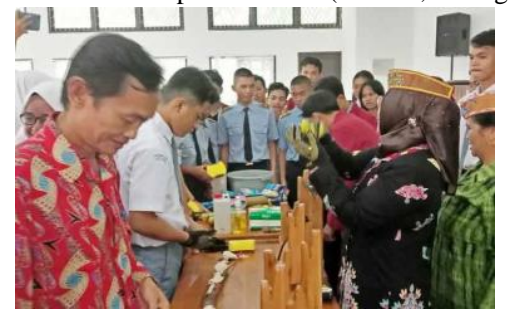

Gambar 2. Mengenalkan cara merawat pusaka (Sumber: borneonews.co.id)

Koleksi pada UPT Museum Balanga terdiri dari berbagai macam jenis klasifikasi yaitu geologika, biologika, etnografika, arkeologika, historika, 
numismatika/heraldika, fisiologika, keramologika seni rupa dan teknologi. Adapun jumlah dari masingmasing koleksi sebagai berikut:

Tabel 3. Koleksi Museum

(Sumber: Arsip UPT Museum Balanga)

\begin{tabular}{|l|l|c|}
\hline No. & \multicolumn{1}{|c|}{ Jenis Koleksi } & Jumlah Koleksi \\
\hline 1 & Geologika & 188 koleksi \\
\hline 2 & Biologika & 233 koleksi \\
\hline 3 & Etnografika & 1.383 koleksi \\
\hline 4 & Arkeologika & 112 koleksi \\
\hline 5 & Historika & 1.116 koleksi \\
\hline 6 & Numismatika/heraldika & 781 koleksi \\
\hline 7 & Filologika & 4 koleksi \\
\hline 8 & keramologika & 572 koleksi \\
\hline 9 & Seni Rupa & 5 koleksi \\
\hline 10 & Teknologika & 53 koleksi \\
\hline & Jumlah Keseluruhan & $\mathbf{5 . 2 8 6}$ koleksi \\
\hline
\end{tabular}

Museum balanga memiliki beberapa jumlah bangunan diantaranya yaitu (1) Gedung utama, (2) Gedung administrasi, (3) Gedung auditorium, (4) Gedung temporer, (5) Gedung perpustakaan, (6) Gedung pameran tetap I dan II, (7) Ruang konservasi koleksi, (8) Gudang koleksi, (9) Ruang pameran khusus bapak Tjilik Riwut. Gedung yang biasanya banyak dikunjungi oleh wisatawan yaitu gedung pameran tetap yang memajang berbagai koleksi yang menunjukkan siklus hidup Suku Dayak.

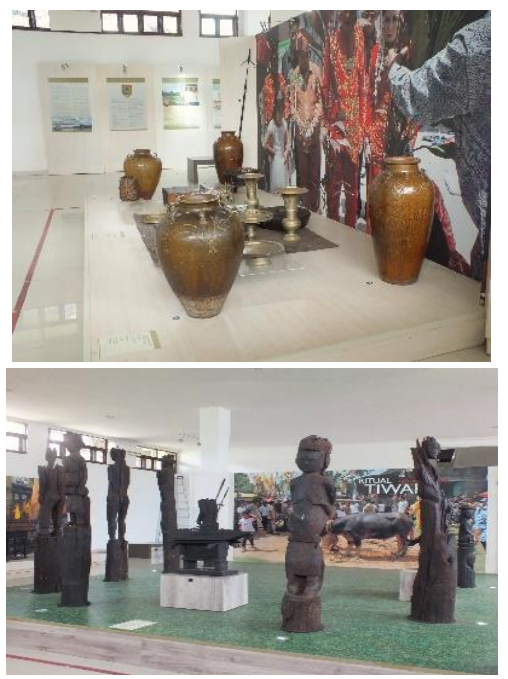

Gambar 3. Ruang Pameran Tetap I dan II (Sumber: Dokumen Pribadi)

Berbeda halnya dengan gedung pameran tetap I dan II, beberapa gedung pameran lainnya ternyata masih belum terkelola dengan maksimal, padahal jika dilihat ada banyak koleksi lainnya di Museum Balanga yang juga tidak kalah menarik. Contohnya pada ruang pameran bapak Tjilik Riwut yang belum mendapat pengelolaan tata ruang maupun tehnik pencahayaan yang tepat sehingga pengunjung biasanya kurang tertarik untuk berswafoto ditempat tersebut. Maliaki memaparkan bahwa keterbatasan pendanaan menjadi kendala dalam tahap pembangunan UPT Museum Balanga sehingga beberapa pengadaan kegiatan harus menggunakan aula yang belum dilengkapi fasilitas yang memadai seperti keperluan pertunjukan, pameran tidak tetap dan lainnya. Dari segi pemasaran yang dijalankan, UPT Museum Balanga memanfaatkan berbagai media seperti website yang tergabung dengan DISBUDPAR yang dalam hal ini berarti website masih belum independen, instagram serta surat-surat yang biasanya diedarkan ke sekolah sampai ke perguruan tinggi.

Dengan demikian, analisis SWOT pada UPT museum balanga sebagai berikut:

\section{Strength-Kekuatan}

1. Memiliki koleksi budaya yang menarik dan unik menunjukan siklus hidup suku dayak.

2. Memiliki ritual adat mamparasih ramu pada setiap tahunnya.

3. Memiliki lokasi yang strategis dan mudah diakses.

4. Memiliki luas mencapai 5 hektar.

5. Harga yang relatif terjangkau.

Weakness-Kelemahan

1. Kurangnya pengelolaan interior dan eksterior seperti ruang pameran, gedung, dan halaman museum.

2. Kurangnya promosi melalui media sosial.

3. Kurangnya servis excellence yang diberikan kepada pengunjung maupun pelayanan melalui media sosial.

\section{Opportunity-Kesempatan}

1. Pertumbuhan wisatawan ke Kota Palangkaraya meningkat pada setiap tahunnya.

2. Dukungan dari berbagai pihak terkait seperti lembaga pendidikan, sanggar seni, maupun berbagai komunitas di Kota Palangkaraya.

Threat-Ancaman

1. Menurunnya minat masyarakat berkunjung ke UPT Museum Balanga.

2. Munculnya museum (objek wisata) lainnya yang lebih menarik di Kota Palangkaraya.

Strategi Alternatif Pemasaran UPT Museum Balanga Sebagai Wisata Edukasi di Kota Palangkaraya :

\begin{tabular}{|l|l|l|}
\hline & Strengths $(\mathrm{S})$ & Weakness $(\mathrm{W})$ \\
& Faktor Kekuatan & Faktor Kelemahan \\
& $\begin{array}{l}\text { 1.Memiliki } \\
\text { koleksi budaya } \\
\text { yang menarik }\end{array}$ & $\begin{array}{ll}\text { 1. Kurangnya } \\
\text { pengelolaan } \\
\text { interior dan }\end{array}$ \\
\hline
\end{tabular}




\begin{tabular}{|c|c|c|}
\hline & $\begin{array}{l}\text { dan unik } \\
\text { menunjukan } \\
\text { siklus hidup } \\
\text { suku dayak. } \\
\text { 2.Memiliki ritual } \\
\text { adat } \\
\text { mamparasih } \\
\text { ramu pada } \\
\text { setiap } \\
\text { tahunnya. } \\
\text { 3.Memiliki } \\
\text { lokasi yang } \\
\text { strategis dan } \\
\text { mudah } \\
\text { diakses. } \\
\text { 4.Memiliki luas } \\
\text { mencapai } 5 \\
\text { hektar. } \\
\text { 5.Harga yang } \\
\text { relatif } \\
\text { terjangkau. } \\
\end{array}$ & \begin{tabular}{|l} 
eksterior \\
seperti ruang \\
pameran, \\
gedung dan \\
halaman \\
museum. \\
2. \\
Kurangnya \\
promosi \\
melalui media \\
sosial. \\
3. \\
Kurangnya \\
servis \\
excellence yang \\
diberikan \\
kepada \\
pengunjung.
\end{tabular} \\
\hline \begin{tabular}{|l}
\multicolumn{1}{|l}{ Opportunities } \\
(O) \\
Faktor Peluang \\
1. Pertumbuhan \\
wisatawan ke \\
Kota \\
Palangkaraya \\
meningkat \\
pada setiap \\
tahunnya. \\
2. Dukungan \\
dari berbagai \\
pihak terkait \\
seperti \\
lembaga \\
pendidikan, \\
sanggar seni, \\
maupun \\
berbagai \\
komunitas di \\
Kota \\
Palangkaraya.
\end{tabular} & $\begin{array}{l}\text { SO } \\
\text { 1. Meningkatkan } \\
\text { kualitas } \\
\text { produk } \\
\text { museum dan } \\
\text { memanfaatkan } \\
\text { sosial media } \\
\text { untuk } \\
\text { menjangkau } \\
\text { promosi } \\
\text { secara lebih } \\
\text { luas (S1, S2, } \\
\text { S5, O1). } \\
\text { 2. Melengkapi } \\
\text { pembangunan } \\
\text { fasilitas untuk } \\
\text { menunjang } \\
\text { kebutuhan } \\
\text { para } \\
\text { wisatawan } \\
\text { (S4, O1) } \\
\text { 3. Memanfaatkan } \\
\text { lokasi yang } \\
\text { strategis untuk } \\
\text { memperluas } \\
\text { kerjasama } \\
\text { dengan } \\
\text { berbagai pihak } \\
\text { terkait seperti } \\
\text { berbagai } \\
\text { universitas, } \\
\text { sekolah dan } \\
\text { lainnya (S3, } \\
\text { O2). }\end{array}$ & \begin{tabular}{|l}
\multicolumn{1}{c}{ WO } \\
1. Melakukan \\
penataan desain \\
interior pemeran \\
dengan menarik \\
serta \\
menghadirkan \\
beberapa kreatif \\
events lainnya \\
sehingga \\
menambah minat \\
wisatawan \\
terutama kaum \\
milenial \\
berkunjung ke \\
Museum \\
Balanga (W1, \\
O1). \\
2. Mengembangkan \\
desain konten \\
visual yang \\
menarik di \\
berbagai situs \\
media sosial \\
sehingga lebih \\
tertata dan \\
pengunjung \\
dapat dengan \\
mudah \\
mengakses \\
semua informasi \\
yang \\
disampaikan ( \\
W2, O1,O2) \\
3. Meningkatkan \\
servis excellence \\
secara langsung \\
maupun melalui \\
sosial media \\
(W3, O1)
\end{tabular} \\
\hline 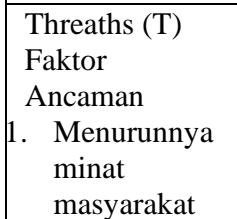 & \begin{tabular}{c}
\multicolumn{1}{c}{$\mathbf{S T}$} \\
1.Memanfaatkan \\
kegiatan ritual \\
dan menambah \\
agenda events \\
rutin lainnya
\end{tabular} & \begin{tabular}{|l}
\multicolumn{1}{c}{ WT } \\
1.Menarik minat \\
masyarakat untuk \\
berkunjung \\
terutama kaum \\
milenial dengan
\end{tabular} \\
\hline
\end{tabular}

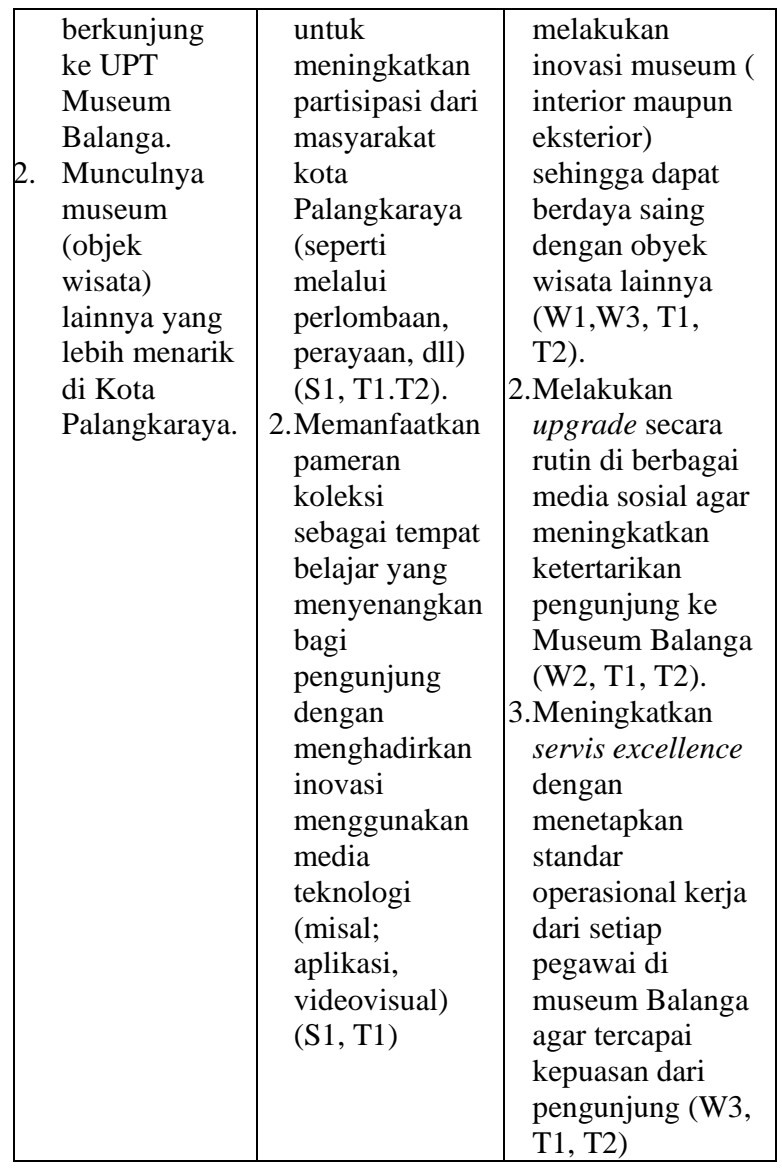

Analisa SWOT diambil berdasarkan kesesuaian dengan faktor internal, eksternal serta peluang dan ancaman. Beberapa kasus Museum seperti pada Museum Omahku Memoriku dalam jurnal Gunawan (2016) dalam melakukan pengembangan pemasaran harus menekankan dari sisi produk dan peningkatan layanan terlebih dahulu. Strategi diferensiasi dapat diterapkan dalam pengembangan museum agar menciptakan keunggulan dari produk tempat wisata lainnya. Selain itu dalam kasus museum lainnya seperti Ullen Sentalu (Ferdinanda, 2016) yang merupakan museum budaya yang cukup terkenal di Yogyakarta menempatkan kepuasan pengunjung terdapat pada kualitas pelayanan yang diberikan oleh pengelola serta bukti fisik dari produk museum menjadi faktor penting yang dinilai oleh pengunjung.

Dengan demikian, berdasarkan analisa SWOT, maka strategi marketing mix di UPT Museum Balanga adalah sebagai berikut :

\section{Segmentasi Pasar}

Segmentasi pasar dilakukan untuk menganalisis calon pengunjung untuk menentukan arah pemasaran yang akan dilakukan. Segmentasi pasar UPT Museum Balanga yaitu berfokus pada pengunjung yang berasal dari sekolah, institusi, komunitas penggiat seni dan budaya maupun peneliti. Adapun kriteria yang dibutuhkan antara lain : (1) segmentasi geografis umumnya pengunjung yang tinggal di Kota Palangkaraya; (2) segmentasi demografis yang tergolong dari usia anak-anak hingga dewasa; (3) segmentasi psikologis dengan 
pengunjung yang dibidik adalah yang memiliki ketertarikan besar untuk mempelajari sejarah, seni maupun budaya dari peninggalan benda-benda pusaka; (4) segmentasi berdasarkan kebutuhan pengunjung misalnya siswa, mahasiswa, ilmuwan, dan sebagainya. Pada pengembangan pemasaran tujuan dari segmentasi pasar diperlukan untuk menetapkan program serta pelayanan yang akan ditawarkan sehingga tepat dengan keinginan pengunjung.

\section{Pemilihan Target Wisatawan}

Pemilihan target wisatawan dilakukan untuk menetapkan sasaran pasar (target market). Berdasarkan hasil dari segmentasi pasar maka yang lebih berorientasi berkunjung ke Museum Balanga adalah pengunjung yang secara berkelompok maupun individual. Pertama, dari kalangan pelajar maupun mahasiswa perguruan tinggi yang berasal dari kota Palangkaraya maupun dari berbagai daerah lainnya yang melakukan studytour. Kedua, wisatawan lokal maupun mancanegara yang memiliki tujuan untuk berekreasi atau kepentingan lainnya. Mengenai hal tersebut maka pihak Museum Balanga disarankan harus menindak lanjuti dengan menyesuaikan konsep dan bentuk produk yang menarik agar dapat diterima sesuai dengan jenis wisatawannya. Selain itu, seleksi media maupun periklanan juga harus dilakukan dengan tepat atau sesuai, karena bentuk dari media juga mempengaruhi ketertarikan dari pengunjung.

\section{Marketing Mix}

Menurut Kotler dan Amstrong (2004) bauran pemasaran merupakan kumpulan alat pemasaran yang bersifat terkendali yang dipadukan oleh perusahaan untuk menghasilkan respon yang diinginkannya di pasar sasaran.

Produk wisata (tourism product) : Pengembangan produk wisata UPT Museum Balanga berfokus untuk memenuhi kebutuhan pengunjung dan menciptakan kepuasan konsumen. Strategi pemasaran produk memanfaatkan analisis SWOT sebagai berikut :

a) Menata ruang museum koleksi Cilik Riwut dan berbagai koleksi lainnya dengan didukung: (1) interior desain yang menarik; (2) tehnik pencahayaan yang sesuai standar museum, (3) mencantumkan informasi lengkap mengenai koleksi (disarankan menggunakan teknologi berupa aplikasi yang dapat discan oleh semua pengunjung), (4) diletakkan didalam tabung kaca (koleksi tertentu) untuk menghindari kerusakan, (5) memilih tema untuk setiap pameran.

b) Membuat agenda rutin seperti exhibition, seminar dan workshop, performance (pertunjukan) dan berbagai perlombaan yang berkenaan dengan seni dan budaya.

c) Menata ulang eksterior desain Museum Balanga agar mendukung swafoto (disarankan menunjukkan karakteristik seni dan budaya Suku Dayak) terutama perbaikan pada taman Museum.

d) Membuat aula yang didukung peralatan teknologi yang mutakhir sehingga dapat digunakan sebagai tempat : (1) penanyangan film, (film dokumenter yang berkaitan dengan sejarah, seni dan budaya), diskusi, perpustakaan dan lainnya. Ditempat ini disarankan disediakan wifi gratis kepada pengunjung.

e) Membuat toko, kafe/restoran yang dapat dimanfaatkan wisatawan untuk bersantai ketika berkunjung. Pengelola UPT Museum Balanga dapat bekerjasama dengan masyarakat yang memiliki usaha kuliner dan kerajinan.

f) Menata ulang area parkir pengunjung supaya memberi kenyamanan bagi yang membawa kendaraan pribadi.

Lokasi wisata (tourism place) : UPT museum balanga memiliki lokasi yang sangat strategis berada di Kota Palangkaraya yang dekat dengan berbagai sekolah maupun perguruan tinggi. Akses menuju museum dapat ditempuh dengan lancar menggunakan kendaraan pribadi maupun berbagai angkutan umum yang tersedia. Kendati demikian, pihak pengelola disarankan selalu mengupgrade website maupun sosial media lainnya untuk memberi informasi selengkapnya mengenai lokasi museum. Selain itu pihak pengelola juga dapat meletakkan papan reklame (plang) yang dibuat dengan menarik sehingga wisatawan tidak kebingungan disaat hendak berkunjung.

Promosi wisata (tourism promotion) : Promosi didefinisikan sebagai kegiatan komunikasi baik secara pribadi dan melalui media massa untuk mempengaruhi orang-orang agar membeli produk. Promosi umumnya terdiri dari periklanan, promosi penjualan, hubungan masyarakat yang dirancang untuk mencapai tujuan tertentu (Middleton dalam Utama, 2016). Promosi dalam pariwisata berbasis teknologi digital yang sedang populer pada saat ini merupakan salah satu bentuk efisiensi yang dapat diterapkan oleh semua pengelola objek wisata (Utama, 2016). Dengan demikian maka strategi promosi pada museum balanga yaitu sebagai berikut:

a) Melalui media sosial (digital) : Pemasaran UPT Museum Balanga dapat dimaksimalkan melalui website, facebook, instagram, dan media sosial lainnya untuk menjangkau pemasaran secara lebih luas. Pengembangan pemasaran yang harus diperhatikan meliputi beberapa aspek diantaranya yaitu (1) membuat konten desain yang menarik, (2) dibuat dalam dua bahasa (bahasa inggris dan bahasa indonesia), (3) mencantumkan informasi selengkapnya mengenai sejarah museum, koleksi yang dimiliki, agenda events, berbagai fasilitas, sekaligus mencatumkan berita atau artikel mengenai museum (4) rutin mengupload konten dalam bentuk foto dan video yang di kemas secara lebih interaktif. Sangat disarankan terutama 
terhadap website agar bersifat independen (terpisah dari website Disbudpar Kalteng), hal ini diperlukan agar semua informasi dapat dituangkan secara lebih lengkap.

b) Menjalin kerjasama dengan berbagai pihak terkait untuk melakukan agenda rutin seperti dengan berbagai sekolah, perguruan tinggi, komunitas, sanggar seni dan sebagainya.

c) Menggunakan direct marketing melalui whatsapp, email, catalog dan sebagainya yang dishare secara langsung kepada masyarakat tentang berbagai informasi kegiatan yang akan dilaksanakan. Penting untuk diperhatikan oleh pihak UPT Museum Balanga agar sebelumnya harus mengumpulkan data pengunjung (disarankan meliputi alamat serta nomer telp/email).

Harga Product (Price) : UPT museum Balanga menetapkan harga Berdasarkan peraturan Daerah Provinsi Kalimantan Tengah Nomor 6 tahun 2013 tentang retribusi masuk UPT Museum "Balanga" yaitu : (1) Pelajar TK/SD Rp 1.000/org; (2) Pelajar SMP/SMA Rp. 2.000/org; (3) Mahasiswa Rp. 2.500/org; (4) Umum Rp. 2.500/org; (5) Pejabat Pusat/Daerah Rp. 3.500/org, (6) Turis Asing : Rp. 15.000/org. Harga yang ditetapkan sudah terjangkau dari berbagai kalangan pengunjung. Sebagai bentuk promosi, UPT Museum Balanga dapat memberikan bonus kunjungan pada hari-hari tertentu. Disarankan harga produk dapat ditingkatkan kembali menyesuaikan dengan perkembangan produk seperti bertambahnya fasilitas dan layanan yang diberikan.

Sumber Daya Manusia (People), semua aktor manusia yang berperan dalam penyediaan layanan harus dapat memainkan perannya masing-masing seperti pegawai perusahaan, konsumen dan konsumen lain. Semua sikap dan tindakan karyawan, cara berpakaian karyawan dan penampilan memberi pengaruh terhadap keberhasilan penyampaian jasa (Utama, 2016: 24). Sistem pelayanan menjadi poin yang harus diperhatikan selain produk secara fisik. Peran para karyawan UPT Museum Balanga yang terlibat menjadi kunci keberhasilan untuk menciptakan kepuasan dari konsumen. Strategi yang dapat dilakukan untuk peningkatan pemasaran yaitu sebagai berikut:

a) Melakukan training servis excellence pada setiap petugas sesuai dengan standar terbaik pelayanan. Sangat disarankan dalam hal ini setiap petugas memiliki kecakapan dalam berbahasa asing.

b) Pentingnya untuk menghadirkan Social Media Spesialist yang akan bertugas melakukan publikasi, kontrol media dan memberi pelayanan kepada masyarakat (customer servis). Social media spesialist bertanggung jawab terhadap semua konten di media sosial dan berkomunikasi secara online kepada masyarakat. c) Setiap petugas disarankan menggunakan kelengkapan seragam yang menarik contohnya busana daerah, atau batik dan lainnya.

d) Setiap petugas UPT Museum Balanga harus selalu dapat melayani pengunjung dengan sigap sabar, ramah dan teliti terutama disaat melayani pengunjung anak-anak dan lansia.

Bukti Fisik (Physical evidance) : penawaran pariwisata merupakan penawaran dari sebuah produk yang tidak berwujud namun konsumen biasanya mencari bukti nyata untuk mengevaluasi produk sebelum mereka membeli atau menggunakan layanan ( George dalam utama, 2016). Bukti fisik memberikan pengaruh terhadap evaluasi tingkat kepuasan dari pengunjung terhadap bentuk produk maupun layanan yang diterima. Pengunjung yang merasa kurang puas umumnya akan merasa kurang tertarik untuk membeli atau berkunjung kembali. Pihak pengelola Museum Balanga harus memperhatikan setiap detail dari ruang pameran yang ditunjukan, seperti lingkungan yang bersih, koleksi yang terawat, dekorasi yang menarik, berbagai fasilitas atau peralatan yang tersedia dan sejenisnya. Pengelola harus secara rutin mengupgrade sosial media

Proses (Process), proses menjadi hal penting yang diperhatikan ketika karyawan berinteraksi dengan pelanggan. Umumnya pelanggan yang berpengalaman menginginkan pelayanan yang terorganisasi, teratur, cepat, nyaman, dan baik seraga, atau disesuaikan (Bennet dalam utama, 2016). Mengenai hal tersebut maka pengelola dianjurkan memberikan servis excellent sesuai dengan harapan. Servis excellent menjadi salah satu faktor penting dalam mencapai tingkat kepuasan pengunjung. Adhianti \& Herlinda (2020) beberapa contoh pelayanan museum lainnya seperti pada Museum Sejarah Jakarta juga tengah memfokuskan pada tingkat servis yang maksimal terutama dalam penggunaan bahasa asing. Hal ini sangat penting untuk diperhatikan mengingat beberapa pengunjung berasal dari negara lain.

a) Pihak pengelola harus memperhatikan efektifitas jumlah pengunjung dalam suatu kelompok kunjungan. Hindari pengunjung yang berdesakan, karena akan sangat mempengaruhi kenyamanan antar pengunjung lainnya.

b) Pihak pengelola harus selalu memastikan antrian yang jelas dan adil terhadap pengunjung sesuai dengan pemandu yang tersedia.

c) Kesiapan dan ketelitian petugas sangat penting untuk diperhatikan oleh karena itu disarankan agar setiap pemandu harus menjalankan training dan melakukan evaluasi kinerja secara rutin dari hasil feedback tingkat kepuasan dari pengunjung. 


\section{PENUTUP}

Strategi pemasaran UPT Museum Balanga diformulasikan agar dapat menjadi alternatif strategi dalam meningkatkan daya tarik dan kunjungan wisatawan lokal maupun mancanegara. Strategi pemasaran menggunakan analisis swot dan marketing mix $7 \mathrm{p}$ yaitu product, price, place, promotion, people, process \& physical evidance. Berdasarkan hasil penelitian maka dapat disimpulkan beberapa faktor kelebihan yang dimiliki oleh Museum Balanga yaitu memiliki segi keunikan dari berbagai museum lainnya. Setiap koleksi yang terdapat di Museum Balanga menunjukkan siklus hidup suku dayak dari proses kelahiran, pernikahan, dan kematian yang dapat menjadi informasi budaya yang menarik kepada pengunjung. Sistem pengelolaan yang berada dibawah tanggungjawab Disbudpar Kalteng menjadikan Museum Balanga alternatif tujuan wisata yang sangat ekonomis dengan letak yang strategis berada di pusat kota Palangkaraya. Beberapa kekurangan yang ditemukan selama penelitian yaitu kurangnya pengelolaan secara fisik seperti desain interior dan eksterior, fasilitas, promosi melalui media sosial dan servis excellence yang diberikan kepada pengunjung. Dengan demikian maka strategi pemasaran UPT Museum Balanga terlebih dahulu harus melakukan optimalisasi terhadap semua produk yang mendukung interior maupun eksterior museum, penambahan fasilitas, rutin membuat event atau agenda lainnya, mengadakan training untuk meningkatkan servis excellence serta merekrut tenaga ahli yang mendukung, menjalin kerjasama dengan pihak luar seperti berbagai sekolah, universitas, komunitas dan lainnya serta rutin dalam membuat konten kreatif melalui media sosial terutama agar menarik perhatian kaum milenial. Berdasarkan kesimpulan tersebut, maka saran yang diajukan terutama kepada pihak pengelola UPT Museum Balanga agar meningkatkan kemampuan dalam fungsi manajemen pemasaran dan pengelolaan baik pada tahap perencanaan (planning), pengorganisasian (organizing), penggerakan (actuating), dan pengawasan (controlling), kemudian meningkatkan jumlah anggaran dalam pengembangan museum, serta pengoptimalan SDM pengelola yang terlibat.

\section{DAFTAR PUSTAKA}

Ardhianti, Anissa Aprilia \& Herlinda. (2020). Strategi Komunikasi Pemasaran 7P Pengelola Museum Sejarah Jakarta dalam Upaya Meningkatkan Daya Tarik Wisatawan Mancanegara- jurnal Scriptura, vol. 1 no. 1

Ardika, I Gede. (2018). Kepariwisataan Berkelanjutan : Rintis jalan lewat Komunitas. Jakarta : PT Kompas Media Nusantara

Daranca, Unira. (2015). "Upaya Peningkatan Wisata di Jakarta Melalui Museum: Strategi Pengembangan Museum Nasional Indonesia" Jurnal Universitas Indonesia.

Ferdinanda. (2016). Analisis Kinerja Pelayanan dan Persepsi Pengunjung Museum Ullen Sentalu dengan metode Importance-Performance Analysis. Institute Seni Indonesia Yogyakarta

Gunawan, Topan Indraseni. (2016). Pengembangan Strategi Tata Kelola Museum Omahku Memoriku- jurnal Tata Kelola Seni, Vol 2 No 1

ICOM (international council of museum). (2019). Museum Definition. Retrieved from http://icom.museum/en/resouces/standardsguidelines/museum-definition/

Kotler, P. dan G. Amstrong. (2004). Dasar-dasar Pemasaran. Edisi Kesembilan. Jakarta: Penerbit Indeks

Nenggala, Munanda Pradana. (2017). Strategi Pengembangan Potensi dan Daya Tarik Museum Tuanku Imam Bonjol di Kabupaten Pasaman. JOM Pekon Vol 4 No 1

Rangkuti, Freddy. (2016). Tehnik Membedah Kasus Bisnis Analisis SWOT. Jakarta: Gramedia

Sunaryo, Bambang. (2013). Kebijakan Pembangunan Destinasi Pariwisata. Yogyakarta: Gava Media

Undang-Undang Nomor 10 Tahun 2009 tentang Kepariwisataan

Utama, I Gusti Bagus Rai. (2016). Pemasaran Pariwisata. Ristekdikti. Universitas Dhayana Pura.

World Tourism Organization "Tourism and the SDGs".http://icr.unwto.org/content/tourismand-sdgs. Diakses Februari 2020 